\title{
PERBEDAAN MODEL PEMBELAJARAN MIND MAPPING DENGAN \\ MODEL PEMBELAJARAN PROBLEM BASED LEARNING \\ DALAM MENINGKATKAN HASIL BELAJAR SISWA PADA MATA PELAJARAN IPA KELAS IV SD NEGERI 068003 MEDAN
}

OLEH:

\author{
DEWI ANZELINA ${ }^{1}$, IIN PARIDA TAMBA ${ }^{2}$ \\ UNIVERSITAS KATOLIK SANTO THOMAS
}

\begin{abstract}
The Objective of the study is to find out difference of Mind Mapping model with Problem Based Learning model to improve student result of lesson on the saince subject in class IV on thing of SD Negeri 068003 Medan. The population are from the first class until the sixth class consist 372 students. The sample using on the research by sampling purposive consist 58. Students the model using on the research is experimental model one group pre-test post-test design that is by giving a pretest before being given treatment and posttest after being treatment. The model in this study uses experimental conducted in two groups, namely experimental I and experimental II. The instrument used to capture data is a multiple choice test in material changes in form objects.

Based on statistical data processing in group I obtained an average result of 66,72 standard deviations 14,21 and a standard error of 2,68 of the total 29 students. For the experimental group II, the average results were 84.31 standard deviations 11,57 and the standard error was 2,18 out of 29 students. By using ttest the writer get the scoring of $t_{\text {scoreis }} 5,119$, if the score calculated with the $t_{\text {score }}>t_{\text {tableis }} 5,199>2,001(0,05)$ so that $H_{0}$ is rejected and the $\mathrm{H}_{\mathrm{a}}$ is accepted. It is mean that the are differences between Mind Mapping model and Problem Based Learning model. So that conclusion Problem Based Learning model is significantly affect than Mind Mapping model on the objects toward the result of lesson on the subject in class IV on thing of SD Negeri 068003 Medan.
\end{abstract}

\section{Keywords: Mind Mapping Model, Problem Based Learning Model and Result of Lesson}

\section{PENDAHULUAN}

\section{Latar Belakang}

Pendidikan memegang peranan sangat penting yang tidak dapat dipisahkan dari kehidupan, dimana sifatnya mutlak baik dalam lingkungan sekitar dan kehidupan sehari-hari.Untuk meningkatkan kualitas pendidikan, berbagai cara 
telah dilakukan dalam dunia pendidikan dimulai dari sekolah dasar hingga perguruan tinggi. Salah satunya adalah dengan meningkatkan mata pelajaran ilmu pengetahuan alam (IPA).IPA merupakan suatu pembelajaran yang berkaitan erat dengan alam.Menurut Sukarno (Widi dan Sulistyowati 2015:23), "IPA adalah sebagai ilmu yang mempelajari tentang sebab dan akibat kejadian yang ada di alam.Dari sekian materi pelajaran IPA, peneliti lebih tertarik mengambil materi pokok perubahan wujud benda.Dalam kegiatan pembelajaran IPA dengan menggunakan materi ini, siswa dapat mengamati perubahan suatu benda melalui praktek langsung.

Berdasarkan hasil wawancara dengan wali kelas IV SD Negeri 068003 Medan dalam pembelajaran IPA, masih sering ditemukan ketidakmaksimalan terhadap hasil belajar yang diperoleh siswa diantaranya adalah: 1) Guru masih dominan menggunakan metode ceramah yang membuat siswa bosan dan bermalas-malasan selama proses pembelajaran berlangsung. 2) Kurangnya guru menggunakan model pembelajaran yang bervariasi dengan menyesuaikan materinya. 3) Hasil belajar siswa rendah, itu dikarenakan pembelajaran masih berpusat pada guru sebagai sumber informasi sehingga pengetahuan siswa masih kurang.

Untuk memperoleh hasil belajar yang lebih baik salah satu upaya yang dilakukan ialah dengan menggunakan model pembelajaranMind Mappingdan Problem Based Learning.Model pembelajaran Mind Mappingmerupakan model pembelajaran yang menggunakan kemampuan dimana siswa diminta untuk membuat suatu gambar berbentuk Mind Mapping berdasarkan materi yang diberikan guru.Problem Based Learning merupakan model pembelajaran yang 
berbasis masalah dimana siswa diminta untuk menyelesaikan suatu permasalahan sesuai dengan pemahaman siswa.Peneliti menggunakan model Mind Mappingdan Problem Based Learningkarena dengan menggunakan model ini siswa ditantang untuk lebih berfikir, mengasah ide-ide, siswa menjadi lebih kreatif, aktif dan dapat memecahkan suatu permasalahan. Berdasarkan uraian di atas, maka peneliti bermaksud mengadakan penelitian dengan mengambil judul Perbedaan Model Pembelajaran Mind Mappingdengan Model Pembelajaran Problem Based Learningdalam Meningkatkan Hasil Belajar Siswa pada Mata Pelajaran IPA Kelas IV SDNegeri 068003 Medan.

\section{Identifikasi Masalah}

Berdasarkan latar belakang di atas dapat disimpulkan identifikasi masalah adalah sebagai berikut.

1. Guru masih dominan menggunakan metode ceramah sehingga siswa merasa bosan danbermalas-malasanselama proses pembelajaran berlangsung

2. Kurangnya guru menggunakan model pembelajaran yang bervariasi dengan menyesuaikan materi.

3. Hasil belajar siswa rendah dikarenakan pembelajaran masih berpusat pada guru sebagai sumber informasi atau masih fokus dengan buku pembelajaran siswa.

\section{Batasan Masalah}

Dalam penelitian perlu adanya pembatasan masalah untuk menghindari kesalah pahaman maksud dan agar lebih efektif dan efisien serta dapat terarah dan tidak terlalu luas jangkauannya.Pembatasan masalah yang dilakukan peneliti yaitu Perbedaan Model Pembelajaran Mind Mapping dengan model pembelajaran 
Problem Based Learningdalam meningkatkan hasil belajar siswa pada mata pelajaran IPA dengan Materi Perubahan Wujud Benda Kelas IV SDNegeri 068003 Medan.

\section{Rumusan Masalah}

Berdasarkan batasan masalah di atas, masalah-masalah yang akan diteliti dapat di rumuskan sebagai berikut:

1. Bagaimana hasil belajar IPA pada pokok bahasan perubahan wujud benda dengan menggunakan model pembelajaran Mind Mappingpada siswa kelas IV SDNegeri 068003 Medan?

2. Bagaimana hasil belajar IPA pada pokok bahasan perubahan wujud benda dengan menggunakan model pembelajaran Problem Based Learning pada siswa kelas IV SDNegeri 068003 Medan?

3. Apakah ada perbedaan penerapan model pembelajaran Mind Mapping dengan Problem Based Learning $(P B L)$ pada hasil belajar IPA menggunakan pokok bahasan perubahan wujud benda pada siswa kelas IV SDNegeri 068003 Medan?

\section{Tujuan Penelitian}

1. Untuk mengetahui hasil belajar IPA pada pokok bahasan perubahan wujud benda dengan menggunakan model pembelajaran Mind Mappingpada siswa kelas IV SDNegeri 068003 Medan

2. Untuk mengetahui hasil belajar IPA pada pokok bahasan perubahan wujud bendadengan menggunakan model pembelajaran Problem Based Learning pada siswa kelas IV SDNegeri 068003 Medan 
3. Untuk mengetahui ada tidaknya perbedaan penggunaan model pembelajaran Mind Mapping denganProblem Based Learning pada hasil belajar IPA menggunakan pokok bahasan perubahan wujud benda pada siswa kelas IVSDNegeri 068003 Medan

\section{METODOLOGI PENELITIAN}

Dalam penelitian ini, peneliti menggunakan metode kuantitatif jenis eksperimen.Teknik pengambilan sampel pada umumnya dilakukan secara random, pengumpulan data menggunakan instrumen penelitian, analisis data bersifat kuantitatif/statistik dengan tujuan untuk menguji hipotesis yang telah ditetapkan.

\section{Lokasi dan Jadwal Penelitian}

Penelitian dilakukan di SD Negeri 068003 pada siswa kelas IV.Tempat penelitian ini beralamat di Jalan Kayu Manis 1 Kecamatan Medan Tuntungan.Penelitian ini dilaksanakan pada semester ganjil tahun pembelajaran $2017 / 2018$

\section{Rancangan/ Desain Penelitian}

Menurut Nurhayat (2016:41-42) Desain penelitian yang akan digunakan ialah One Group Pretest-Postest Designyaitu dengan memberikan pretest sebelum diberi perlakuan dan postest setelah diberi perlakuan. Desain penelitian ini dapat digambarkan sebagai berikut:

\section{Tabel One Group Pretest-Postest Design Desain Eksperimen}

\begin{tabular}{|l|l|l|l|}
\hline $\mathrm{E} 1$ & $\mathrm{O}_{1}$ & $\mathrm{X}_{1}$ & $\mathrm{O}_{2}$ \\
\hline $\mathrm{E} 2$ & $\mathrm{O}_{3}$ & $\mathrm{X}_{2}$ & $\mathrm{O}_{4}$ \\
\hline
\end{tabular}




\section{Populasi dan Teknik Pengambilan Sampel}

Populasi dalam penelitian ini adalah semua siswa kelas I sampai dengan kelas VI di SD Negeri 068003 Medan Tahun Pembelajaran 2017/2018 yang jumlah siswanya sebanyak 372 siswa.

\section{Teknik Pengambilan Sampel}

Dalam penelitian ini, peneliti menggunakan teknik pengambilan sampel di kelas IVA dan kelas IVB dimana sampel merupakan suatu bagian dari populasi.

\section{Jumlah Siswa kelas IV SD Negeri 068003 Medan Tahun Pembelajaran 2017/2018}

\begin{tabular}{|c|c|c|}
\hline NO & Kelas & Jumlah Siswa \\
\hline 1 & IVA & 29 \\
\hline 2 & IVB & 29 \\
\hline & Jumlah & 58 \\
\hline
\end{tabular}

Sumber dari sekolah SD Negeri 068003 Medan

\section{Jenis dan Sumber Data}

Data merupakan sekumpulan informasi yang berbentuk nyata.Jenis data pada penelitian ini adalah jenis data primer yaitu data berupa hasil belajar siswa yang dilakukan peneliti secara langsung. Sumber data dalam penelitian ini berasal dari sekolah tempat peneliti.Jumlah sampel sebanyak 58 orang siswa yang terdapat di kelas IVA dan IVB SD Negeri 068003 Medan, yang diberikan materi tentang perubahan wujud benda.

\section{Teknik Pengumpulan Data}

Untuk mendapatkan data dalam penelitian ini, peneliti menggunakan tes sebagai teknik pengumpulan data. Tanpa mengetahui teknik pengumpulan data, maka peneliti tidak akan mendapatkan data yang memenuhi standar data yang ditetapkan. Menurut Arikunto (2017) bahwa tes adalah instrumen yang berupa tes 
ini dapat digunakan untuk mengukur kemampuan dasar dan pencapaian atau prestasi.

\section{Uji Instrumen Penelitian}

\section{Instrumen Penelitian}

Instrumen penelitian atau alat pengumpulan data merupakan suatu alat untuk memperoleh data dan tes objektif bentuk pilihan berganda pada materi perubahan wujud benda.Penyusunan instrumen ini mengacu pada ranah kognitif Taksonomi Bloom yang sudah direvisi yaitu mulai dari C1 - C3.

\section{Uji kualitas instrumen}

Dalam menguji kualitas instrumentersebut menggunakan alat ukur validitas dan reliabilitas.Menurut Arikunto (2017:211) validitas adalah suatu ukuran yang menunjukkan tingkat-tingkat kevalidan atau kesahihan suatu instrumen.Sebelum diberikan pretest dan postest peneliti terlebih dahulu melakukan uji instrumen soal ke sekolah lain yaitu ke Sekolah SD Swasta Santo Thomas 5 Medan.

Untuk menguji validasi instrumen dilakukan dengan menggunakan rumus pearson/product moment, yaitu (Arikunto,2017:213)

$\mathrm{r}_{\mathrm{Xy}}=\frac{\mathrm{N} \Sigma \mathrm{XY}-(\Sigma \mathrm{X})(\Sigma \mathrm{Y})}{\left\{\mathrm{N} \Sigma \mathrm{X}^{2}-\left(\Sigma \mathrm{X}^{2}\right)\right\}\left\{\left(\mathrm{N} \Sigma \mathrm{Y}^{2}-\left(\Sigma \mathrm{Y}^{2}\right)\right\}\right.}$

Hasil perhitungan uji validitas instrumen soal dengan menggunakan program SPSS ver 22pada tabel 3.6 maka diperoleh soal yang valid sebanyak 20 butir soal dari 35 butir soal. Jadi, soal yang 20 digunakan untuk postest dan apabila siswa dapat mengerjakan keseluruhan soal postestakan mendapat nilai 100. Cara penilaiannya jumlah jawaban benar dikalikan 5 (lima). 
Selain menggunakan alat ukur validitas peneliti juga menggunakan alat ukur reliabilitas.MenurutArikunto(2016:115) untuk menguji reliabilitas tes penelitian digunakan K-R. 20 dengan rumus sebagai berikut:

$$
\mathrm{r}_{11}=\left(\frac{n}{n-1}\right)\left(\frac{S^{2}-\Sigma p q}{S^{2}}\right)
$$

Berikut adalah hasil perhitungan uji reliabilitas item soal dengan menggunakan pengolahan program SPSS ver 22pada tabel seperti berikut ini:

Tabel

\section{Reliability Statistics}

\begin{tabular}{|c|c|}
\hline Cronbach's Alpha & N of Items \\
\hline .796 & 20 \\
\hline
\end{tabular}

Hasil uji reliabilitas pada tabel 3.6 adalah 0,796 , jika dilihat pada tabel pedoman interpretasi koefisien korelasi di atas nilai reliabilitas terletak pada tingkatan 0,60 - 0,799 sehinggadikatakan bahwa kualifikasi pada hasil uji reliabilitas adalah kuat

\section{Teknik Pengolahan Data (Analisis)}

Pengolahan data adalah suatu proses untuk memperoleh data atau angka dengan menggunakan rumus-rumus tertentu. Analisis tersebut dapat dilakukan dengan langkah-langkah seperti di bawah ini:Menghitung rata-rata, standar deviasi, standard eror, uji normalitas, uji homogenitas dan uji hipotesis. 


\section{HASIL DAN PEMBAHASAN}

\section{Pengolahan Data Eksperimen I}

Setelah pengumpulan data dilakukan, maka langkah berikutnya adalah mengolah data dan membuat tabel distribusi frekuensi. Hal ini guna mengetahui rata-rata (mean), standar deviasi, dan standar error dari data tes pilihan berganda pada eksperimen I menggunakan model Mind Mapping terdapat nilai ratarata(mean) sebanyak 66,72, standar deviasi sebanyak 14,21, standar eror sebanyak 2,68 .

\section{Pengolahan Data Eksperimen II}

Data-data sebagaimana disajikan pada halaman sebelumnya, akan dideskripsikan dengan tabel distribusi. Pada tabel distribusi tersebut dapat dicari nilai rata-rata (mean), standar deviasi, dan standar errormelalui perhitungan pada eksperimen II menggunakan model $P B L$ terdapat nilai rata-rata (mean) yaitu84,31, standar deviasi sebanyak 11,57 dan standar errorsebanyak 2,18.

\section{Pengujian Prasyarat Analisis}

\section{Uji Normalitas}

Menurut Lubis (2015:55) mengatakan bahwa uji normalitas diadakan untuk mengetahui normal atau tidaknya populasi penelitian tiap variabel penelitian.

Tabel di bawah ini adalah hasil perhitungan uji normalitas dengan pengolahan data menggunakan program SPSS ver 22. 
Tabel Uji Normalitas

One-Sample Kolmogorov-Smirnov Test

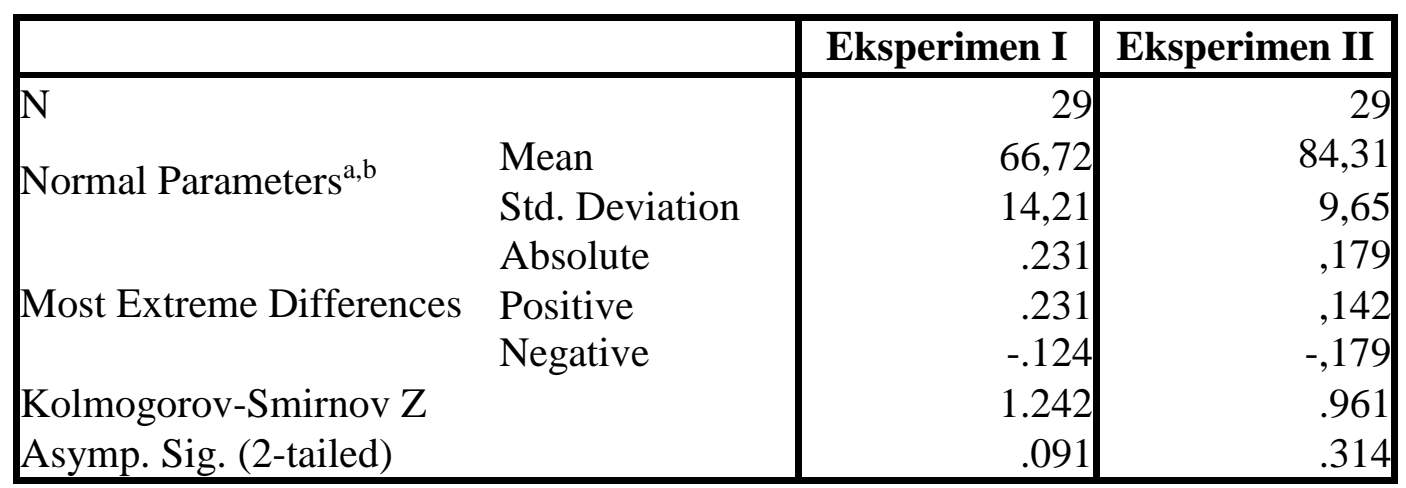

a. Test distribution is Normal.

b. Calculated from data.

Hasil uji normalitas pada kolmogorav-smirnov menunjukkan jika signifikan > 0,05, maka nilai signifikan kelas eksperimen I berdistribusi normal yaitu 0,091 > 0,05 dan nilai signifikansi kelas eksperimen II berdistribusi normal yaitu $0,314>0,05$.

\section{Uji Homogenitas}

Menurut Lubis (2015:66) Uji homogenitas adalah untuk memperlihatkan bahwa dua atau lebih kelompok data sampel berasal dari populasi yang memiliki variansi yang sama. Tabel di bawah ini adalah hasil perhitungan uji homogenitas dengan pengolahan data menggunakan program SPSS ver 22.

Tabel Uji HomogenitasTest of Homogenity of Variances

\begin{tabular}{|c|c|c|c|}
\hline Levene Statistic & $\begin{array}{c}\text { df1 (degree of } \\
\text { freedom) }\end{array}$ & $\begin{array}{c}\text { df2 (degree of } \\
\text { freedom) }\end{array}$ & Sig. \\
\hline 1.873 & 2 & 56 & .177 \\
\hline
\end{tabular}


Dapat dilihat dari tabel tersebut bahwa nilai signifikansi 0,177 . Hal ini menunjukkan nilai tersebut lebih dari 0,05 maka $\mathrm{H}_{0}$ diterima karena nilai signifikan $0,177>0,05$. Itu berarti data mempunyai varian yang homogen (sama).Dalam tabel tersebut terdapat df1 dan df2 dimana df1 adalah sebagai numerator atau penyebut dan df2 sebagai denumerator atau pembilang. Contoh adalah pada uji homogenitas, dimana df1 sebagai penyebut adalah menunjukkan jumlah banyaknya variabel bebas. Sedangkan denumerator menunjukkan jumlah observasi atau jumlah sampel dikurangi jumlah variabel bebas.

\section{Pengujian Hipotesis}

Uji hipotesis digunakan untuk mengetahui apakah $H_{0}$ (Hipotesis Nihil) diterima atau ditolak.Pengujian hipotesis pada penelitian ini dilakukan dengan menggunakan “uji t”.Menurut Lubis (2015:117) bahwa Uji t adalah uji kesamaan dua rata-rata digunakan untuk mengetahui ada atau tidak ada perbedaan (kesamaan) antara dua buah data.Berikut Tabel di bawah ini yang merupakan hasil perhitungan uji-t dengan pengolahan data menggunakan program SPSS ver 22. 


\section{Hasil Uji-t}

Independent Samples Test

\begin{tabular}{|c|c|c|c|c|c|c|c|c|c|c|}
\hline & \multicolumn{2}{|c|}{$\begin{array}{c}\text { Levene's } \\
\text { Test for } \\
\text { Equality of } \\
\text { Variances }\end{array}$} & \multicolumn{7}{|c|}{ t-test for Equality of Means } \\
\hline & & \multirow[b]{2}{*}{$\mathrm{F}$} & \multirow[b]{2}{*}{ Sig. } & \multirow[b]{2}{*}{$\mathrm{T}$} & \multirow[b]{2}{*}{ Df } & \multirow{2}{*}{$\begin{array}{l}\text { Sig. } \\
(2- \\
\text { tailed } \\
\quad)\end{array}$} & \multirow{2}{*}{$\begin{array}{l}\text { Mean } \\
\text { Diffe } \\
\text { rence }\end{array}$} & \multirow{2}{*}{$\begin{array}{l}\text { Std. } \\
\text { Error } \\
\text { Diffe } \\
\text { rence }\end{array}$} & \multicolumn{2}{|c|}{$\begin{array}{c}95 \% \\
\text { Confidence } \\
\text { Interval of the } \\
\text { Difference }\end{array}$} \\
\hline & & & & & & & & & Lower & $\begin{array}{c}\text { Uppe } \\
\text { r }\end{array}$ \\
\hline $\begin{array}{l}\text { Total } \\
\text { _skor }\end{array}$ & $\begin{array}{l}\text { Equal } \\
\text { variances } \\
\text { assumes } \\
\text { Equal } \\
\text { variances } \\
\text { not } \\
\text { assumes }\end{array}$ & 2,695 & , 106 & $\begin{array}{r}5,11 \\
9 \\
5,11 \\
9\end{array}$ & $\begin{array}{r}54,6 \\
65\end{array}$ &, 000 & 3,448 & ,674 & 2,099 & 4,798 \\
\hline
\end{tabular}

Tabel di atas menunjukkan bahwa hasil uji t pada grup eksperimen memiliki nilai $t_{\text {hitung }}$ sebesar 5,119. Jika nilai itu dikonsultasikan dengan nilai $t_{\text {tabel }}$ pada derajat kebebasan (degree of freedom) $=58$ dimana $t_{\text {hitung }}$ $>t_{\text {tabelyaitu5,119>2 }} .001(0,05)$ maka $\mathrm{H}_{0}$ ditolak dan $\mathrm{H}_{\mathrm{a}}$ diterima. Itu berarti ada perbedaan antara model pembelajaran Mind Mapping dengan PBL terhadap hasil belajar IPA di kelas IV SD Negeri 068003 Medan.

\section{Pembahasan Hasil Penelitian}

Dari hasil penilaian tersebut diperoleh nilai rata-rata pretest sebesar 50,68. Setelah pretest selesai selanjutnya penilaian hasil belajar siswa diberikan perlakuan dengan menggunakan model pembelajaran Mind Mapping (nilai postest) memiliki rentangan nilai antara $50-95$. Dari hasil penilaian tersebut diperoleh nilai rata-rata postest sebesar 66,72 dan termaksud kategori cukup. 
Dari hasil penilaian tersebut diperoleh nilai rata-rata pretes sebesar 53,27. Setelah Penilaian hasil belajar siswa pretest selanjutnya hasil belajar siswa setelah diberikan pengajaran dengan menggunakan model pembelajaran $P B L$ (nilai postest) yang memiliki rentangan nilai antara 60 - 100. Dari perolehan nilai tersebut diperoleh nilai rata-rata postest sebesar 84,31.

Sesuai dengan hasil penelitian bahwa nilai hasil belajar IPA materi "Perubahan Wujud Benda" dengan menerapkan model pembelajaran Mind Mapping pada siswa kelas IVA SD Negeri 068003 termaksud cukup yaitu 66,72karena sudah di atas nilai Kriteria Ketuntasan Minimum (KKM) yaitu 65. Nilai hasil belajar IPA materi "Perubahan Wujud Benda" dengan menggunakan model PBLpada siswa kelas IVB SD Negeri 068003 termaksud baik yaitu 84,31

Perbedaan model Mind Mappingdengan $P B L$ ini juga dapat dilihat dari hasil uji t pada grup eksperimen memiliki nilai $t_{\text {hitung }}$ sebesar 5,119. Jika nilai itu dikonsultasikan dengan nilai $t_{\text {tabel }}$ pada derajat kebebasan (degree of freedom) $=58$ dimana $t_{\text {hitung }}>\mathrm{t}_{\text {tabel }}$ yaitu 5,119 $>0,05$ maka $\mathrm{H}_{0}$ ditolak dan $\mathrm{H}_{\mathrm{a}}$ diterima. Itu berarti ada perbedaan antara model pembelajaran Mind Mapping dengan $P B L$ terhadap hasil belajar IPA pada peserta didik kelas IV SD Negeri 068003 Medan.

\section{PENUTUP}

\section{Simpulan}

Berdasarkan uraian yang telah dikemukakan pada bab sebelumnya, maka dapat dikemukakan beberapa simpulan dari penelitian ini yaitu: 
1. Nilai rata-rata postestyang diperoleh siswa SD Negeri 068003 Medan tahun pembelajaran 2018/2019 dengan menggunakan model Mind Mapping adalah 66,72 berada dalam kategori cukup.

2. Nilai rata-rata postestyang diperoleh siswa SD Negeri 068003 Medan tahun pembelajaran 2018/2019 dengan menggunakan model $P B L$ adalah 84,31 berada dalam kategori Baik.

3. Bahwa perbedaandiantara kedua model menunjukkan bahwa model $P B L$ lebih baik dibandingkan dengan model Mind Mapping. Berdasarkan perhitungan dengan uji-t dengan syarat sig $(2$-tailed $)<0,05$ hasil uji t yang diperoleh lebih besar dari tabel yaitu 5,119>0,05 maka hipotesis nihil $\left(\mathrm{H}_{\mathrm{o}}\right)$ ditolak dan hipotesis alternatif $\left(\mathrm{H}_{\mathrm{a}}\right)$ diterima.Itu artinya ada perbedaan yang signifikan terhadap hasil belajar IPA menggunakan model Mind Mapping dan hasil belajar siswa menggunakan model pembelajaran $P B L$ pada peserta didik kelas IV SD Negeri 068003 Medan.

\section{Saran}

Berdasarkan pembahasan dari kesimpulan, implikasi dan keterbatasan penelitian

di atas maka peneliti memberikan beberapa saran yaitu:

1. Kemampuan siswa perlu ditingkatkan lagi. Hal tersebut tentunya membutuhkan model pembelajaran yang lebih efektif untuk digunakan dalam belajar mengajar di sekolah. Salah satu model pembelajaran yang dapat dijadikan sebagai alternatif adalah model pembelajaran $P B L$. 
2. Siswa disarankan agar lebih efektif mengikuti kegiatan pembelajaran yang selama ini dilaksanakan, serta lebih aktif berdiskusi yang dapat menambah wawasan dan ilmu pengetahuan.

3. Bagi peneliti yang akan datang dan berminat untuk mengembangkan hasil penelitian ini, perlu dilakukan penelitian pada mata pelajaran lain dan di sekolah yang berbeda.

4. Guru hendaknya dapat menggunakan model pembelajaran yang bernilai efektif sesuai dengan materi pelajaran yang disampaikan, sehingga siswa merasa tidak dibebani oleh model ataupun metode yang menyebabkan ia merasa jenuh dan bosan ketika mengikuti kegiatan pembelajaran.

5. Kepala sekolah sebagai tempat atau wadah mendidik agar lebih memperhatikan saran dan sistem pengajaran guna meningkatkan mutu pengajaran khususnya bidang mata pelajaran IPA.

\section{DAFTAR PUSTAKA}

Adiyatmaningsih, N Pt Harini dkk. 2014. Berjudul Model Pembelajaran Berbasis Masalah Berbantuan Mind Mapping Berpengaruh Terhadap Hasil Belajar IPA Siswa Kelas V Sd Gugus III Gianyar.Jurnal pdf.

Amri, Sofan. 2016. Pengembangan dan Model Pembelajaran dalam kurikulum 2013. Jakarta :Prestasi Pustaka.

Arikunto,Suharsimi.2017.Prosedur Penelitian. Jakarta: Rineka Cipta

Chandramica, FriezsyaPuti. 2017. Berjudul Pengaruh Penerapan Model Pembelajaran Mind Mapping Terhadap Hasil Belajar IPSPada Siswa Kelas IV SD Negeri 2 Gunung Terang Bandar lampung.Skripsi PDF Universitas Lampung

Dymiati dan Mudjiono. 2013. Belajar dan pembelajaran. Jakarta : PT RinekaCipta.

Huda, Miftahul. 2017. Model-Model Pengajaran dan Pembelajaran. Yogyakarta: Pustaka Pelajar 
Haryanto.2012. Sains untuk SD/MI kelas IV. Jakarta: Erlangga

Istarani. 2012. Model Pembelajaran Inovatif. Medan: Media Persada

Istarani dan Pulungan Intan . 2016. Ensiklopedia Pendidikan. Medan : Larispa

Kurniasih,Imas dan Sani Berlin. 2016. Ragam Pengembangan Model Pembelajaran.Yogyakarta:Kata Pena

Lubis, Asnarni. 2015. Statistik SPSS IBM 22. Medan

Margono. 2010. Metodologi Penelitian Pendidikan. Jakarta :Rineka Cipta

Ngalimun.2014. Strategi dan Model Pembelajaran.Banjarmasin : Aswaja Pressindo

Nurhayat. 2016. Perbandingan Model Kooperatif Tipe Two Stay Two Stray dan Think Pair Share terhadap hasil belajar IPS Siswa Kelas V SD Negeri 10 Metro Pusat. PGSD FKIP Universitas Lampung.

PrihatnaniErlina Dan Pradipta Dany Kurniawan. 2017. Perbandingan Hasil Belajar Dari Penerapan MetodeMind Mapping Dan Problem Based LearningBerbantu Media Audiovisual Pada Pembelajaran IpaSiswa Kelas Iv Sdn Gugus Gajah MadaKabupaten Semarang Tahun Pelajaran 2016/2017.PGSD FKIP Universitas Kristen Satya Wacana

Purwanto. 2017. Evaluasi Hasil Belajar. Surakarta : Pustaka Pelajar

Sanjaya,Wina. 2017. Strategi Pembelajaran Berorientasi Standar Proses Pendidikan. Jakarta: Kencana Prenadamedia Group

Saputri, Ristia Puji. 2017. Pengaruh Model Pembelajaran Problem Based Learning Terhadap Hasil Belajar Tematik Pada Siswa Kelas V Di Sekolah Dasar Negeri 2 Labuhan Ratu Bandar Lampung.Skripsi PDF Universitas Lampung.

Setyosari, Punaji. 2012. Metode penelitian pendidikan dan pengembangan. Jakarta : Kencana

Shoimin, Aris. 2016. Model Pembelajaran Inovatif dalam kurikulum 2013. Yogyakarta: ArRuzz Media.

Suarjana MD, Pd Md Hendra Kesuma, I Md Tegeh. 2017. Pengaruh Model Problem Based Learning Berbantuan Mind Mapping Terhadap Hasil Belajar IPA Siswa Kelas V. Jurnal PGSD Universitas Pendidikan Ganesha 
Sudijono, Anas. 2012. Pengantar Statistik Pendidikan. Jakarta: PT Raja grafindo Persada

Sudjana. 2016. Metoda Statistika. Bandung: PT Tarsito

Sugiyono. 2017. Metode Penelitian Pendidikan. Bandung: Alfabeta

Sugiyono. 2017. Metode Penelitian Kuantitatif,Kualitatif dan R\&D. Bandung: Alfabeta

Susanto, Ahmad. 2016. Teori Belajar dan Pembelajaran. Jakarta: Prenadamedia Group

Tampubolon,Saur. 2013. Penelitian Tindakan Kelas. Jakarta: Erlangga

Wisudawati, Widi, Asih dan Sulistyowati Eka. 2015. Metodologi Pembelajaran IPA.Jakarta: PTBumi Aksara 